\title{
Replacing canes with an elasticated orthotic-garment in chronic stroke patients - The influence on gait and balance. A series of $\mathrm{N}-\mathrm{of}-1$ trials
}

Citation for published version (APA):

Maguire, C. C., Sieben, J. M., Lutz, N., van der Wijden, G., Scheidhauer, H., \& de Bie, R. A. (2020). Replacing canes with an elasticated orthotic-garment in chronic stroke patients - The influence on gait and balance. A series of N-of-1 trials. Journal of Bodywork and Movement Therapies, 24(4), 203-214. https://doi.org/10.1016/j.jbmt.2020.06.006

Document status and date:

Published: 01/10/2020

DOI:

10.1016/j.jbmt.2020.06.006

Document Version:

Publisher's PDF, also known as Version of record

\section{Document license:}

Taverne

Please check the document version of this publication:

- A submitted manuscript is the version of the article upon submission and before peer-review. There can be important differences between the submitted version and the official published version of record.

People interested in the research are advised to contact the author for the final version of the publication, or visit the DOI to the publisher's website.

- The final author version and the galley proof are versions of the publication after peer review.

- The final published version features the final layout of the paper including the volume, issue and page numbers.

Link to publication

\footnotetext{
General rights rights.

- You may freely distribute the URL identifying the publication in the public portal. please follow below link for the End User Agreement:

www.umlib.nl/taverne-license

Take down policy

If you believe that this document breaches copyright please contact us at:

repository@maastrichtuniversity.nl

providing details and we will investigate your claim.
}

Copyright and moral rights for the publications made accessible in the public portal are retained by the authors and/or other copyright owners and it is a condition of accessing publications that users recognise and abide by the legal requirements associated with these

- Users may download and print one copy of any publication from the public portal for the purpose of private study or research.

- You may not further distribute the material or use it for any profit-making activity or commercial gain

If the publication is distributed under the terms of Article 25fa of the Dutch Copyright Act, indicated by the "Taverne" license above, 
Prevention and Rehabilitation

\title{
Replacing canes with an elasticated orthotic-garment in chronic stroke patients - The influence on gait and balance. A series of N-of-1 trials
}

\author{
Clare C. Maguire ${ }^{\text {a, b, d, f, * , Judith M. Sieben }}{ }^{\text {b, c }}$, Nathanael Lutz ${ }^{\text {a }}$, Gisela van der Wijden ${ }^{\text {d }}$, \\ Heike Scheidhauer ${ }^{a}$, RobertA. de Bie ${ }^{\text {b,e }}$ \\ ${ }^{a}$ Department of Physiotherapy, Bildungszentrum Gesundheit Basel-Stadt, 4142, Muenchenstein, Switzerland \\ ${ }^{\mathrm{b}}$ Caphri School for Public Health and Primary Care Research, Maastricht University, 6200, MD, Maastricht, the Netherlands \\ ${ }^{\mathrm{c}}$ Department of Anatomy and Embryology, Maastricht University, 6200, MD, Maastricht, the Netherlands \\ ${ }^{\mathrm{d}}$ Department of Physiotherapy, REHAB, Clinic for Neurorehabilitation and Paraplegiology, Basel, Switzerland \\ e Department of Epidemiology, Maastricht University, 6200, MD, Maastricht, the Netherlands \\ ${ }^{\mathrm{f}}$ Department of Health, Bern University of Applied Science, Schwarztorstrasse 48, 3007, Bern, Switzerland
}

\section{A R T I C L E I N F O}

\section{Article history:}

Received 3 February 2019

Received in revised form

2 March 2020

Accepted 7 June 2020

\section{Keywords:}

Cerebrovascular stroke

Canes

Orthoses

Walking

Postural balance

\begin{abstract}
A B S T R A C T
Objective: To investigate the effect of replacing canes with an elasticated orthotic-garment on balance and gait-function in chronic stroke survivors.

Design: Experimental, $\mathrm{N}$-of-1 series with a replicated, $\mathrm{ABC}$ design with randomised phase duration in a home setting.

Participants: Four cane using chronic stroke survivors (P1-4).

Interventions: Phase A (9-12 weeks) cane-walking "as usual" to establish baseline values; Phase B (9-16 weeks) intervention: orthotic-garment worn throughout the day with maximal cane-use reduction; Phase C (9-10 weeks) participant-determined follow-up: either no walking-aid, orthotic-garment or cane.

Outcome measures: Primary: Functional-Gait-Assessment (FGA), Secondary: Trunk-sway during walking measured as Total-Angle-Area $\left(\mathrm{TAA}^{\circ 2}\right.$ ) in frontal and sagittal-planes, both measured weekly.

Results: Visual and statistical analysis of results showed significant improvements in FGA from phase A to B in all participants. Improvement continued in phase C in P2, stabilized in P1 and P4 and deteriorated in P3. A Minimal-Clinical-Important-Difference of 6 points-change was achieved in P2 \& P4. Trunk-sway reduced during walking, indicating increased stability, in two participants from phase $A$ to $B$ and in three participants from $A$ to $C$ but no TAA changes were statistically significant. In phase $C$ participant-selected walking-aids were: P1 cane-usage reduced by $25 \%$, P2 independent-walking with no assistive-device, S3 usual cane-usage, $\mathrm{P} 4$ orthotic-garment with reduced cane-usage 2-3 days-a-week, usual cane-usage 4-5 days.

Conclusions: Although walking ability is multifactorial these results indicate that the choice of walkingaids can have a specific and clinically relevant impact on gait following stroke.

"Hands-free" assistive-devices may be more effective than canes in improving gait-function in some patients.

Clinicaltrials.gov id: NCT03642444.
\end{abstract}

() 2020 Elsevier Ltd. All rights reserved.

\footnotetext{
* Corresponding author. Bern University of Applied Science, Department of Health, Schwarztorstrasse 48, 3007, Bern, Switzerland.

E-mail address: clare.maguire@bfh.ch (C.C. Maguire).
}

\section{Introduction}

Maximizing recovery and Quality of Life (QoL), characterised by independence in Activities of Daily Living (ADLs) and social participation, are consistently identified patient goals following stroke (Brown et al., 2014; van Mierlo et al., 2016; Wang and 
Langhammer, 2017). Gait dysfunction has been identified as the most powerful predictor of activity and participation limitations in stroke survivors (Andrenelli et al., 2015). Reduced balance, musclestrength and cardiovascular fitness contribute significantly to diminished gait function in these patients (Michael et al., 2005; Patterson et al., 2007). A vicious cycle appears to be established in which low levels of ambulation lead to further deconditioning with consequent reductions in gait function and social participation (Fini et al., 2017; Norlander et al., 2016; Paul et al., 2016).

A greater understanding of factors influencing the recovery of walking ability and the impact of specific interventions on these processes may enable the optimisation of treatment plans. Although gait control is multifactorial (Patterson et al., 2007; Verma et al., 2012), studies suggest that walking-aids such as canes and walkers have a specific and relevant impact on recovery. A number of prospective observational studies have demonstrated that balance and falls efficacy are reduced in stroke patients who regularly used walking-aids (Kim and Kim, 2015; Paquet et al., 2009), that stroke patients using canes long-term have lower balance scores and show less social participation than those who do not (Hamzat and Kobiri, 2008), and that the sensorimotor function of the non-hemiplegic, cane holding hand is significantly reduced compared to non-cane using stroke patients (Son et al., 2012). These results appear to support studies in the general population which indicate a high positive correlation between walking aid use and fall risk (West et al., 2015). However, to date no causal relationship between cane use and gait-function has been established through experimental studies following stroke. Research has primarily investigated the immediate impact of canes on kinematic and kinetic parameters in cross-sectional studies and authors widely conclude that walking-aids positively influence gait (Allet et al., 2009; Cha, 2015; Tyson, 1999). A recent Clinical Practice Guideline recommended the use of walking aids following stroke (Veerbeek et al., 2014). It should be considered however, that as hand-held walking-aids influence parameters such as the use of "ankle and hip" balance strategies (Bateni and Maki, 2005; Maki and McIlroy, 1997), reduce hemiplegic muscle activity during cane walking (C. Maguire, Sieben, Frank and Romkes, 2010), unload hip joints (Ajemian et al., 2004; Neumann, 1999a) and require the use of hands, which likely disrupts the pattern of healthy gait control in spinal circuitry (Dietz, 2003), the long-term influence on gait-function remains unclear.

We suggest that for stroke patients without a high risk of falling (Maeda et al., 2015), walking-aids should preferably allow the use of healthy balance strategies, should not reduce muscle activity or joint loading and should not require the use of hands. Studies indicate that an elasticated orthotic-garment and strapping system, TheraTogs, fulfils these criteria (C. Maguire et al., 2010; C. Maguire et al., 2016).

The aim of this study was therefore to investigate the influence of the elasticated orthotic-garment on gait-function and balance when combined with personalised, maximum reduction of caneuse in chronic stroke patients.

\section{Methods}

\subsection{Study design}

This study was conducted according to the CONSORT extension for N-of-1 trials (CENT, 2015) (Vohra et al., 2016). N-of-1 trials are appropriate for testing the effectiveness of interventions in chronic, stable conditions particularly if patient groups are heterogeneous, displaying varying comorbidities and concurrent therapies (Vohra et al., 2016). As randomized control trials are not able to predict whether treatments will be effective for a specific individual, $\mathrm{N}$-of1 trials have been categorised as Level 1 evidence (the strongest category) for evaluating treatment effects and harms in individuals (OCEBM, 2011).

The study design was an experimental, N-of-1 series with an $A B C$ design with randomised period duration (Hart and Bagiella, 2012; Vohra et al., 2016).

1st phase A - cane walking "as usual" and baseline measurements.

2nd phase B - orthotic-garment intervention and cane use reduction.

3rd phase $\mathrm{C}$-participant-determined follow-up intervention.

\subsubsection{Randomization}

Randomization of time periods of 1 st phase A, 2nd phase B and 3rd phase $C$, was performed to improve internal validity, which is potentially threatened by time related changes in the dependent variables(Hart and Bagiella, 2012). The randomized phase duration was computer generated by one member of the study staff (JS) at Maastricht University. Time-periods were not disclosed to the primary researcher $(\mathrm{CM})$ until after patient enrolment. Randomization for each participant and for all phases was performed at the beginning of the study. Time periods for phase A were between 9 and 12 weeks, phase B between 9 and 16 weeks, for phase $C$ between 9 and 10 weeks.

\subsubsection{Participants}

Participants consisted of a convenience sample of four patients recruited from the physiotherapy out-patient department of the REHAB Basel, Switzerland. Clinic for Neurorehabilitation and Paraplegiology.

Inclusion criteria were:

1. Chronic stroke (>six months since last stroke). 2. Independent cane walkers. Participants usually used canes to walk inside (this could intermittently change e.g. from cane to holding furniture etc.) and always when outside. 3. A Mini Mental State Score of 22 or above (Folstein et al., 1975).

\section{Exclusion criteria were:}

1. Patients at risk of falling identified as a Berg Balance Score $\leq 42$ / 56 (Tilson et al., 2012).

\subsubsection{Intervention}

Orthotic-garment fitting: At the end of Phase A participants were individually fitted with the orthotic-garment which was applied to support hemiplegic hip extensor and abductor musculature (Fig. 1). The upper-and lower body parts of the orthosis were tailored to ensure comfortable neck, arm and leg fit. Elastic straps were applied to facilitate muscle activity. One end of the strap was sewn onto the garment and the second attachment position was marked to enable daily, standardised fitting. Caregivers were taught in as many sessions as necessary (2-3) how to fit and remove the orthotic garment. Trained physiotherapy staff first demonstrated application of the orthotic garment. The intended effect of the orthosis was explained. The importance of correct application for safety, comfort and effectiveness was emphasized. Caregivers then applied the orthotic garment under supervision until they felt confident in the correct and independent application. Written and photographic instructions were provided. Caregivers were family members and nursing care staff for participants 1,2 and 4. For participant 3 , physiotherapy staff in the rehabilitation clinic fit the orthosis as no support was available at home. The orthosis was fitted to wear beneath undergarments to allow toileting without having to remove it (not shown in Fig. 1.). 

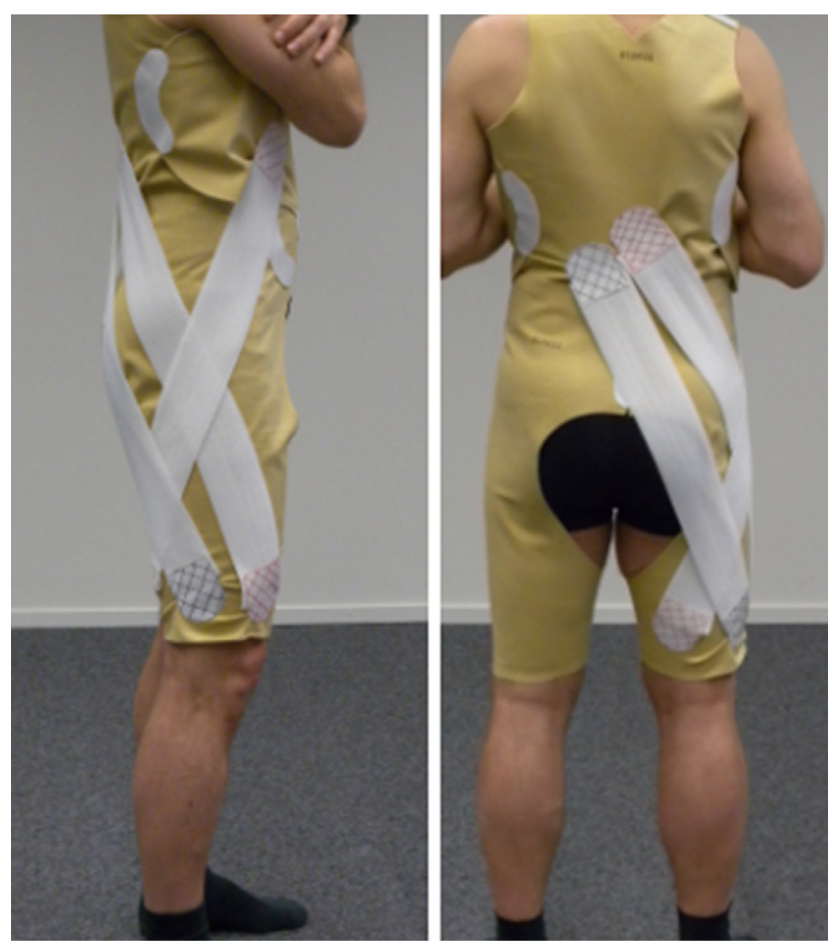

Fig. 1. Elasticated orthotic-garment with straps applied to support hemiplegic hip extensor and abductor musculature. Subjects wore undergarments above the orthosis (not shown here).

Walking practice without cane - When the individualised orthotic-garment was ready, walking with the garment and without a cane was practiced on 3 occasions for 15-20 min with a physiotherapist. Caregivers were present on at least one occasion. This enabled familiarisation and preparation for phase $\mathrm{B}$.

\subsubsection{Trial phase description}

1st phase A - cane walking "as usual" and baseline measurements. Participants continued to walk as usual with a cane for a period of 9-12 weeks, during which time outcomes were measured weekly to establish baseline values.

2nd phase B - orthotic-garment intervention and cane use reduction. Participants walked with the fitted orthotic garment and with reduced cane use for a period of 9-16 weeks. The orthosis was applied when dressing in the morning and removed before bed at night. Participants were instructed to reduce cane use as much as possible and to walk only with the orthotic-garment. Caregivers were offered ongoing support as necessary. Outcomes were measured weekly in the morning before the orthosis was applied. The garment was then fitted after measurement by physiotherapy staff in the REHAB, Basel clinic.

3rd phase $\mathrm{C}$ - participant-determined follow-up intervention. Participants walked with a participant-determined assistive device for a period of 9-10 weeks. Choice was based on the experience of phases A \& B and options therefore included: cane use alone with or without reduction of usage, continued use of the orthoticgarment with or without cane, independent walking without assistive device. Outcomes were measured weekly under the same conditions as in phases A \&B.

\subsubsection{Standard therapy}

All participants were receiving out-patient physiotherapy, occupational therapy and where indicted, speech therapy once or twice weekly prior to and during the study. This continued independently of the study.

\subsubsection{Outcome Measures}

All measurements were carried out without any walking-aids, once a week during the baseline phase $\mathrm{A}$, intervention phase $\mathrm{B}$ and follow-up phase $C$ periods. The primary outcome was the Functional Gait Assessment (FGA) (Price and Choy, 2018; Thieme et al., 2009; Wrisley \& Kumar, 2010; Wrisley et al., 2004) which has been shown to be a valid and reliable tool for measuring functional gait ability in stroke patients and is translated and validated for a German speaking population (Thieme et al., 2009). This test assesses postural stability during various walking tasks with 10 -items, each item being scored on a scale from 0 to 3 . This measure takes five to $10 \mathrm{~min}$ to complete and was therefore considered practical for weekly measurements. Higher scores indicate improvement in gait function.

The secondary outcome was trunk-sway measured as trunk angular displacement when walking using the SwayStar balance system (Balance International Innovations $\mathrm{GmbH}$, Iseltwald, Switzerland) (Allum and Carpenter, 2005; Allum et al., 2002). The SwayStar system consists of two angular velocity sensors (fibreoptic gyroscopes) which are attached to a belt and worn by the participants at the level of L2/3 (Centre of Mass (CoM)). Trunksway is measured as peak-to-peak angular displacement of the $\mathrm{CoM}$ in the frontal and sagittal planes during walking. The sensors are connected to PC software via a Bluetooth communication, which sample velocity signals every $100 \mathrm{~ms}$ and numerically integrate the velocity signals to yield angular displacement. From these parameters the Total Angle Area of trunk displacement (TAA) was calculated in degrees ${ }^{2}$. Measurements were taken weekly during an $8 \mathrm{~m}$ walk. Lower scores indicate reduced trunk displacement, indicating increased stability and improved gait function.

\subsubsection{Recording of orthotic-garment and cane use}

Participants or carergivers were asked to record the number of hours the orthotic-garment was worn each day during Phase $B$ and to estimate cane-use as a percentage of normal cane-use (phase A values). This was reported weekly during measurement sessions. A Likert scale questionnaire was also completed weekly during phase $B$ regarding the subjective effect on walking ability and comfort level when wearing the orthotic-garment.

\subsubsection{Adherence}

Satisfactory adherence was defined as wearing the orthotic garment for at least $85 \%$ of days in phase B for a minimum of $6 \mathrm{~h}$ per day combined with maximal cane-use reduction.

\subsubsection{Ethical approval and blinding}

The Ethics Committee of Canton Basel, Switzerland granted ethical approval. No blinding of participants, care providers or assessors was implemented because of practical difficulties arising from the nature of the interventions. To minimise measurement bias, measurements were carried out by two assessors (either together or alternating at regular intervals) to ensure standardised measurement procedures and to scrutinize performance interpretation.

\subsubsection{Statistics}

2.1.10.1. Power analysis - sample size (number of measurements per phase). In N-of- 1 trials statistical power depends on the number of measurements per phase. A power analysis was conducted to determine the number of measurements necessary in each phase to detect significant differences between phases with alpha set at 0.05 and a power (1-beta) of 0.80 .

As no studies have directly estimated a minimal clinically significant difference for the FGA in chronic stroke patients, these values were estimated based on the following information: 
- Mean score of the FGA in healthy adults age 60-70 - score 27, age 70-80 - score 25 (Walker et al., 2007).

- Estimated mean of chronic stroke patients based on Lin et al. and Thieme et al. score 15 (Lin et al., 2010; Thieme et al., 2009).

- The included participants were not at risk of falling (exclusion criteria). Studies estimate a cut-off score for predicting falls with the FGA is between 15 for Parkinsons (Leddy et al., 2011) and 20-22 for community dwelling older adults (Wrisley \& Kumar, 2010).

- We therefore assumed our patients would have a minimum score of 15 ranging to a maximum of 22 . We estimated a mean value of 19 . Improvement to achieve independent walking without a walking aid would mean reaching a score of an unimpaired elder of 25 points. This is a clinically important difference of 6 points.

Therefore $\mu(0)=19, \mu(1)=25 \sigma=7$. Based on these values sample size i.e. adequate number of measurements per phase is 9 . We determined measurements should be separated by at least one week.

2.1.10.2. Statistical analysis. As no gold-standard for the analysis of single case data exists, it is recommended that several statistical methods are combined and compared to improve the validity of data interpretation (Deng et al., 2013; Nourbakhsh and Ottenbacher, 1994).

Data was plotted graphically and assessed visually for changes in level, trend and variability between baseline, intervention and follow-up phases (Backman and Harris, 1999; Marklund and Klässbo, 2006). The median and Inter-Quartile-Range were calculated for FGA scores and for trunk-sway (angular excursion in the sagittal and frontal planes of the Centre of Mass) during walking in each phase. Box plots were created for visual analysis of differences between phases.

Several methods were used for statistical analysis, including the split method of trend estimation, Friedmans Anova and post-hoc Wilcoxon-signed-ranks tests to test for statistically significant differences between phases and finally Cohen's d for different sized groups to estimate the effect-size between phases.

The split method of trend estimation, also called the „celeration line“, is a method commonly used to analyse single case experimental data (Alan, 2010; Deng et al., 2013). A trend line is calculated in the baseline phase using median values in the first and second half of that phase to determine the gradient of the slope. While maintaining the gradient, the position of the slope-line is adjusted so that $50 \%$ of the data points fall above the line and $50 \%$ fall below. This line is then extended through the intervention phase $\mathrm{B}$ to provide a visual guide for predicting outcome over time if the trend had remained unchanged in the next phase (assuming no effect of intervention). As such, the celeration line tests the hypothesis that there is no difference in outcome across the two phases. If in phase B, $50 \%$ of the data points remain above and $50 \%$ below the celeration line, then it may be concluded that there was no change in outcome resulting from introduction of the treatment (Backman and Harris, 1999). If this is not the case, the percentage of observed data points above or below the line is subtracted from the baseline value to give an indication of the magnitude of the trend change (Byiers et al., 2012). This procedure is repeated from the intervention (B) to the follow-up phase (C).

\section{Results}

\subsection{Patient characteristics}

Participant baseline characteristics are presented in Table 1 and a summary of each patient's clinical presentation, analysed according to the International Classification of Functioning Disability and Health (ICF) (Ustun et al., 2003), is presented in Table 2.

Four cane using, chronic stroke survivors (P1 -P4) with a mean (SD) time since stroke in years of 4.5 (1.6) participated in the study.

Clinical presentation at baseline based on an International Classification of Functioning, Disability and Health (ICF) analysis.

\subsubsection{Protocol adaptations}

All participants reduced or stopped cane use and replaced this with an elasticated orthotic garment, TheraTogs, over a period of 8-16 weeks in phase B. Participants 1, 2 and 4 wore the orthoticgarment seven days a week. Participant 3, wore the orthosis only three days a week due to difficulty with application each morning. For P3 the orthotic garment was fitted in the morning three days a week by staff in the (name removed for blinded copy) when attending out-patient physiotherapy. This represents $100 \%$ of defined adherence levels. All participants wore the orthosis on all days possible for a minimum of $6 \mathrm{~h}$ (range $8-1.3 \mathrm{~h}$ ). This was combined with individual levels of cane reduction.

Participant 2 was randomised to a period of 14 weeks in phase B, however due to improvements in balance and walking, he requested to stop using either the orthotic-garment or a cane after 8 weeks. He therefore transitioned into phase $C$ after 8 weeks and walked independently without any assistive devices. Participant 3 was randomised to a period of 13 weeks in phase B. However, as he was only able to wear the orthotic-garment three days a week he requested to have this period extended, and continued for 19 weeks. Due to 3 weeks absence for vacation TheraTogs was worn for 16 weeks.

Patient or carer reported time wearing the orthotic-garment, percentage cane use in phase $\mathrm{B}$ compared to usual use and individually selected phase $C$ assistive-device are presented in Table 3.

The subjective influence of the orthotic-garment on walking ability and comfort levels are presented in Fig. 2. At the end of every week in phase B, each participant completed two Likert scale questionnaires. Question 1 asked "In the last week what was the effect of TheraTogs on walking?" with six possible answers from "helped walking very much" to "made walking very difficult".

Table 1

Baseline demographic characteristics.

\begin{tabular}{|c|c|c|c|c|c|c|c|}
\hline Participant & Age & Gender & Type of stroke & $\begin{array}{l}\text { Hemiplegic } \\
\text { side }\end{array}$ & $\begin{array}{l}\text { Time since stroke in years } \\
\text { (months) }\end{array}$ & $\begin{array}{l}\text { Height } \\
(\mathrm{m})\end{array}$ & BMI \\
\hline 1 & 50 & $\mathrm{~F}$ & $\begin{array}{l}\text { Bilateral cerebral ischemic infarct -Middle Cerebral Artery M1 proximal left, M1 } \\
\text { distal right. }\end{array}$ & Right & $4(1)$ & 1.72 & 23 \\
\hline 2 & 56 & M & $\begin{array}{l}\text { Ischemic infarct left Middle Cerebral Artery following spontaneous carotid artery } \\
\text { dissection }\end{array}$ & Right & $6(1)$ & 1.77 & 25 \\
\hline 3 & 46 & M & Traumatic Internal carotid artery dissection right & Left & $2(6)$ & 1.88 & 23 \\
\hline 4 & 58 & M & $\begin{array}{l}\text { Ischemic infarct left Middle Cerebral Artery following spontaneous carotid artery } \\
\text { dissection }\end{array}$ & Right & $5(7)$ & 1.78 & 32 \\
\hline
\end{tabular}


Table 2

Clinical presentation at baseline based on an International Classification of Functioning, Disability and Health (ICF) analysis.

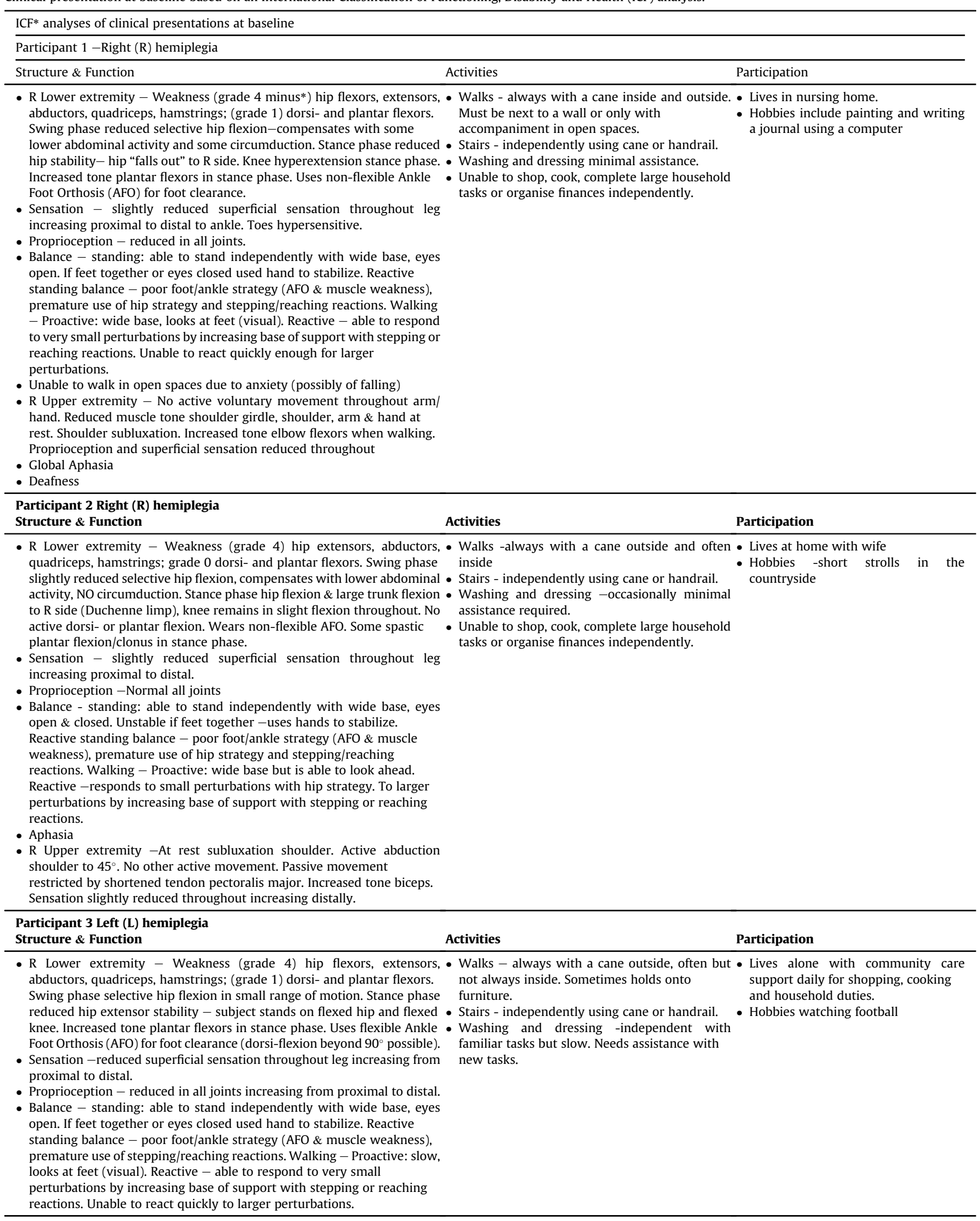


Table 2 (continued)

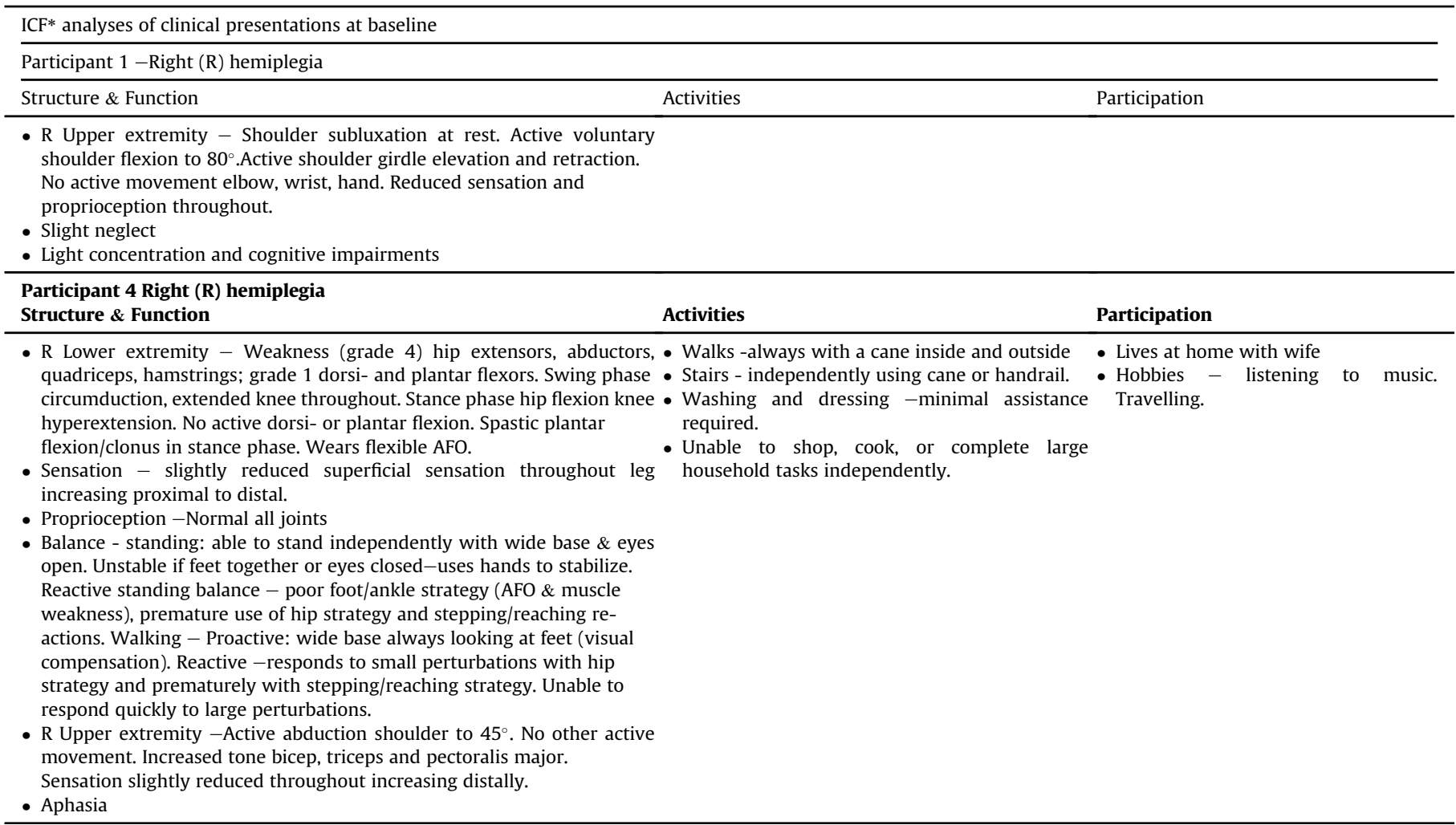

Table 3

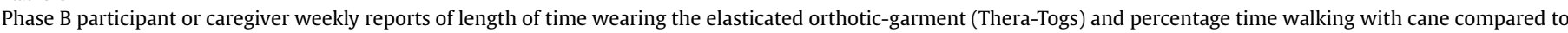
usual cane use.

\begin{tabular}{|c|c|c|c|c|}
\hline & Subject 1 & Subject 2 & Subject 3 & Subject 4 \\
\hline \multicolumn{5}{|l|}{ Phase B orthotic-garment wear } \\
\hline $\begin{array}{l}\text { Reported orthotic-garment wear per day in } \\
\text { hours (mean(SD)) }\end{array}$ & $11.3(1.9)$ & $10.0(0.0)$ & $8(2.9)$ & $9.5(2.4)$ \\
\hline Total number of weeks/days worn & $12 / 84$ & $8 / 56$ & 16/48 (3 days per week) & $9 / 63$ \\
\hline Total number of hours worn & 949.2 & 560 & 384 & 598.5 \\
\hline \multicolumn{5}{|l|}{ Phase $B$ cane-usage (\% of usual usage) } \\
\hline $\begin{array}{l}\text { Reported weekly cane use as a percentage of } \\
\text { usual (phase A) use (mean (SD)) }\end{array}$ & $25.5(13)$ & $3(5.5)$ & $\begin{array}{l}1.5 \text { (4) (for } 3 \text { days a week } \\
-48 \text { days in total) }\end{array}$ & $50.4(21.5)$ \\
\hline $\begin{array}{l}\text { Consequent mean reduction of cane use in } \\
\text { phase B }\end{array}$ & $74.5 \%$ for 84 days & $97 \%$ for 56 days & $98.5 \%$ for 48 days & $49.6 \%$ for 63 days \\
\hline \multicolumn{5}{|l|}{ Phase $C$ participant selected assistive device } \\
\hline & $\begin{array}{l}\text { Reduced cane-use to } 75 \% \\
\text { of baseline phase A }\end{array}$ & $\begin{array}{l}\text { Independent walking with } \\
\text { no assistive-device }\end{array}$ & $\begin{array}{l}\text { Unchanged cane-use as } \\
\text { baseline phase A }\end{array}$ & $\begin{array}{l}\text { TheraTogs } 2-3 \text { times a week and } \\
\text { baseline cane-use on other days }\end{array}$ \\
\hline
\end{tabular}

Question 2 asked "In the last week how comfortable did Thera-Togs feel on average?" with six possible answers from "very comfortable" to "painful". Fig. 2 presents the number of times each participant gave each answer. All answers were on the positive side of the scale with the majority in the top two categories.

\subsubsection{Effects on gait and balance}

Changes in FGA scores and trunk-sway across phases are as presented visually with Celeration Lines in Fig. 3, as raw values with statistical analysis in Table 4 and as box plots in Fig. 4.

Fig. 3 shows FGA and trunk-sway data plotted against time. Visual analysis demonstrates jumps in FGA values between phases $A$ and $B$ for all participants i.e. when using the orthotic-garment and reducing cane use. From phases B to C, FGA scores reduced for all except participant 2 who used neither cane nor the orthosis in phase C. In participant $1,83 \%$ of measurement points in $B$ are above the extended celeration line from A, indicating a $33 \%$ improvement from baseline. In participants $2,3 \& 4$ all points are above the line, indicating at least $50 \%$ improvement. In phase C, $66 \%$ of measurement points from participant 1 are below the extended celeration line from $\mathrm{B}$, indicating a $16 \%$ deterioration, participant 2 shows a $12.5 \%$ improvement from B to C, participants 3 and 4 show at least $50 \%$ deterioration, as all measurement points fall below the extended celeration line.

Reduced values of trunk-sway indicate increased stability and balance improvement. In participant 1 trunk-sway measurements from $A$ to $B$ remained distributed evenly around the extended celebration line, indicating no change. Participants $2 \& 4$ showed a $50 \%$ and 39\% improvement respectively. Participant 3 showed a 50\% deterioration. From phase B to C participant 1 showed a $17 \%$ deterioration, participant 2 a 17.5\% improvement, participants 3 and 4 a deterioration of at least $50 \%$.

All participants showed statistically significant improvements in FGA scores from phase A to phase B with large effect sizes. 


\section{In the last week what was the effect of TheraTogs on walking?}

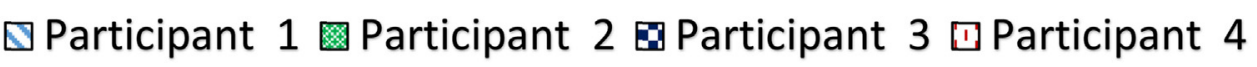

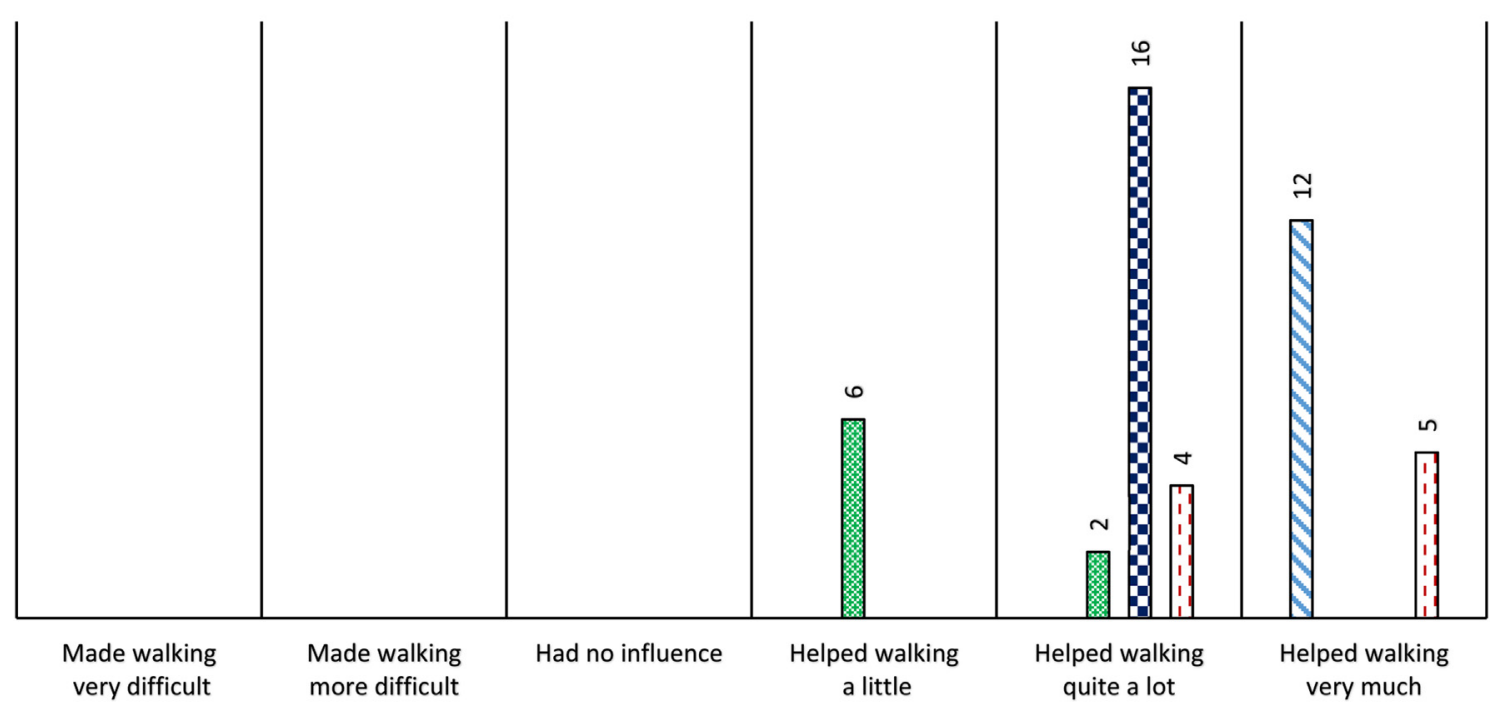

\section{In the last week how comfortable did thera-togs feel on average?}

\section{Participant 1 Participant $2 \square$ Participant $3 \square$ Participant 4}

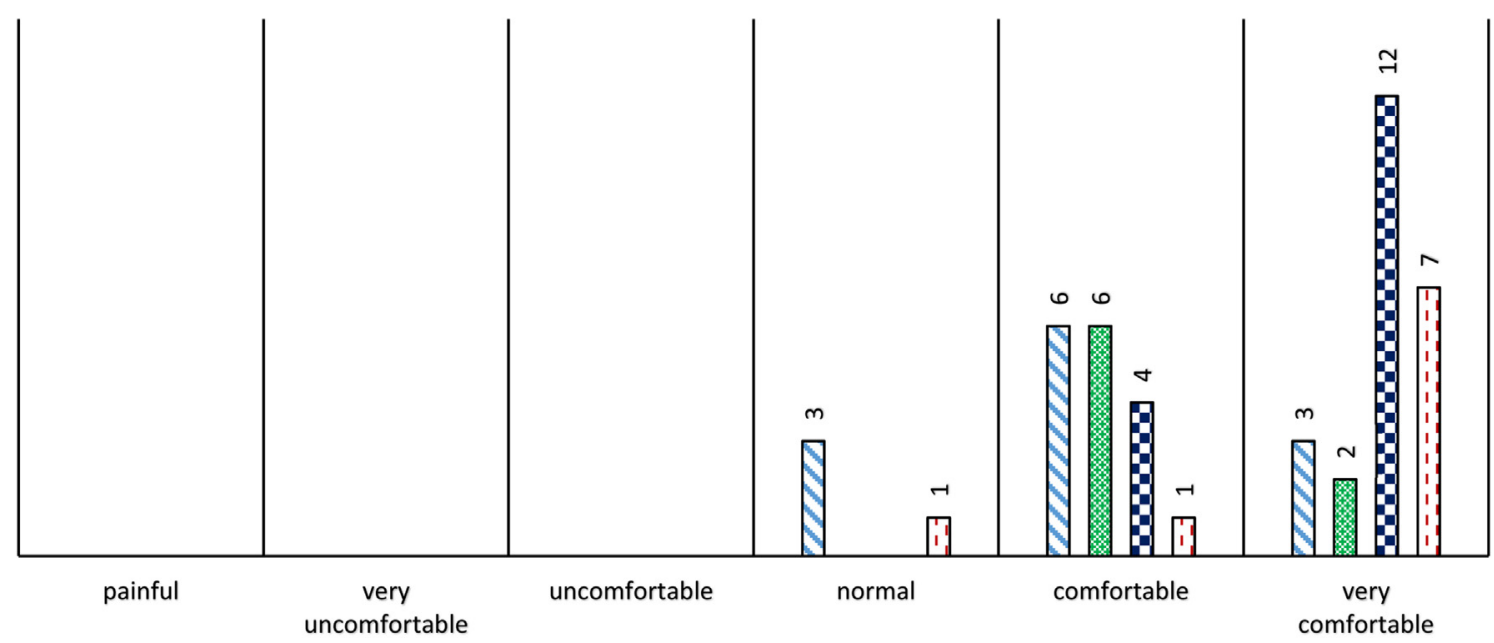

Fig. 2. The subjective influence of the orthotic-garment on walking ability and comfort levels Bars represent the number of times each answer was given by each participant.

Participant 4 scores showed an improvement exceeding the Minimal-Clinical-Important-Difference (MCID) of 6 points between phases $A$ to $B$ and participant 2 between $A$ and C. Trunk-sway improved (reduced) in participants 1,2 and 4 from phase A to phase B although changes were not statistically significant. Effectsizes were small to medium but not significant.

\section{Discussion}

These $n$-of- 1 trials examined the effect of an elasticated orthotic-garment concurrent with reduced cane use on gait and balance for chronic stroke survivors. To our knowledge, this is the first experimental, prospective study to investigate the causal effect of cane use on gait function and balance in chronic stroke survivors.

All participants showed improvements in the primary outcome, FGA, between phase A - "as-usual" cane use and phase B - reduced cane use and replacement with TheraTogs. All data analyses confirmed this improvement. These changes suggest that although gait function and recovery following stroke are influenced by a myriad of factors, the type of assistive walking device used has a specific influence. This may be explained by the physiological effects of walking-aids on structures and processes such as joint loading and input from peripheral afferents which influence activity in spinal-cord circuitry (Dietz, 2012; Dietz et al., 2002), alterations in muscle action (Buurke et al., 2005; C. Maguire et al., 


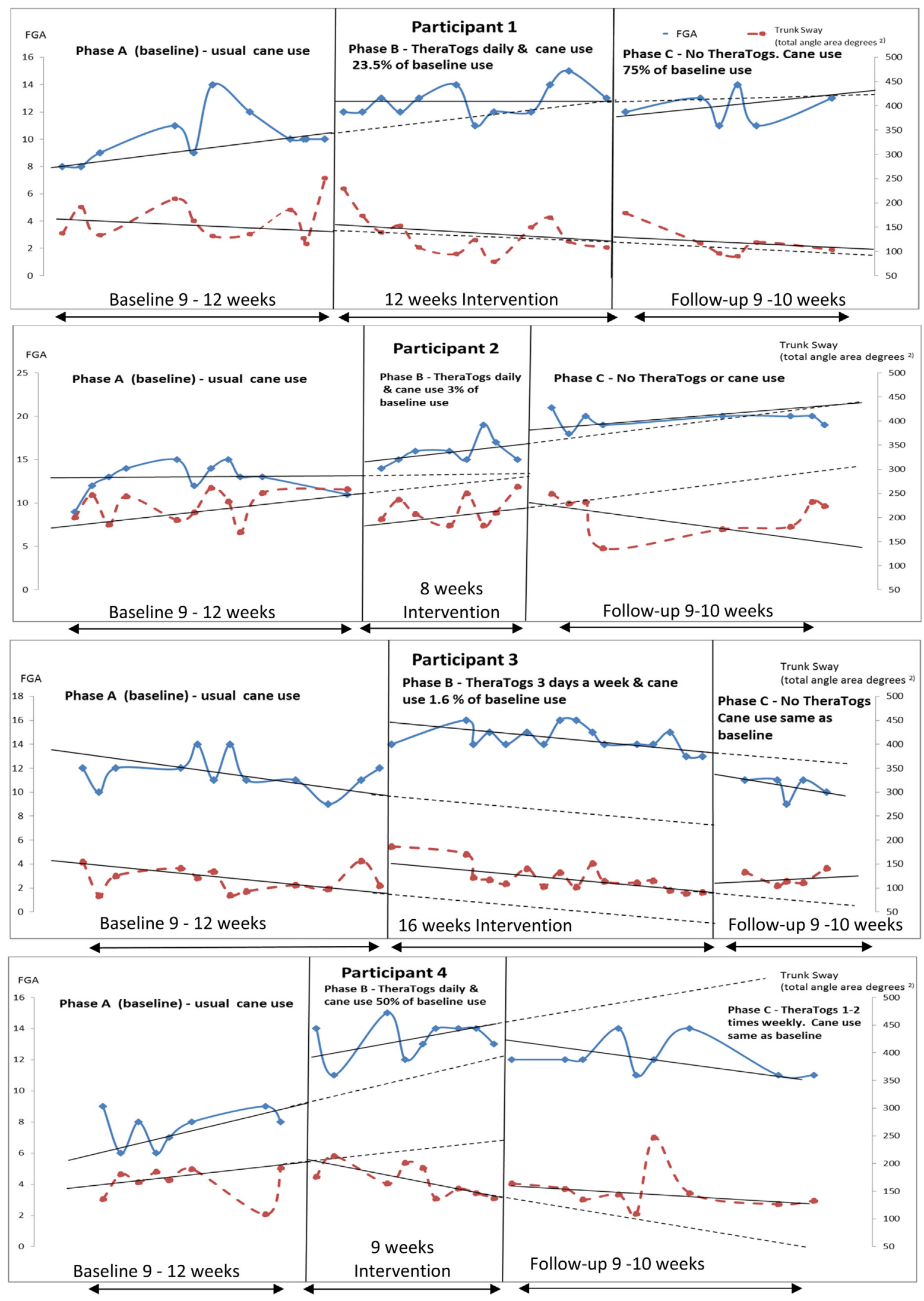

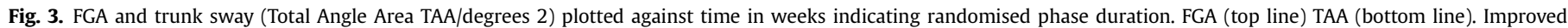
outcomes indicated by: FGA higher scores, TAA lower scores. 
Table 4

Changes in FGA scores and trunk-sway across phases - raw data, p-values and effect sizes.

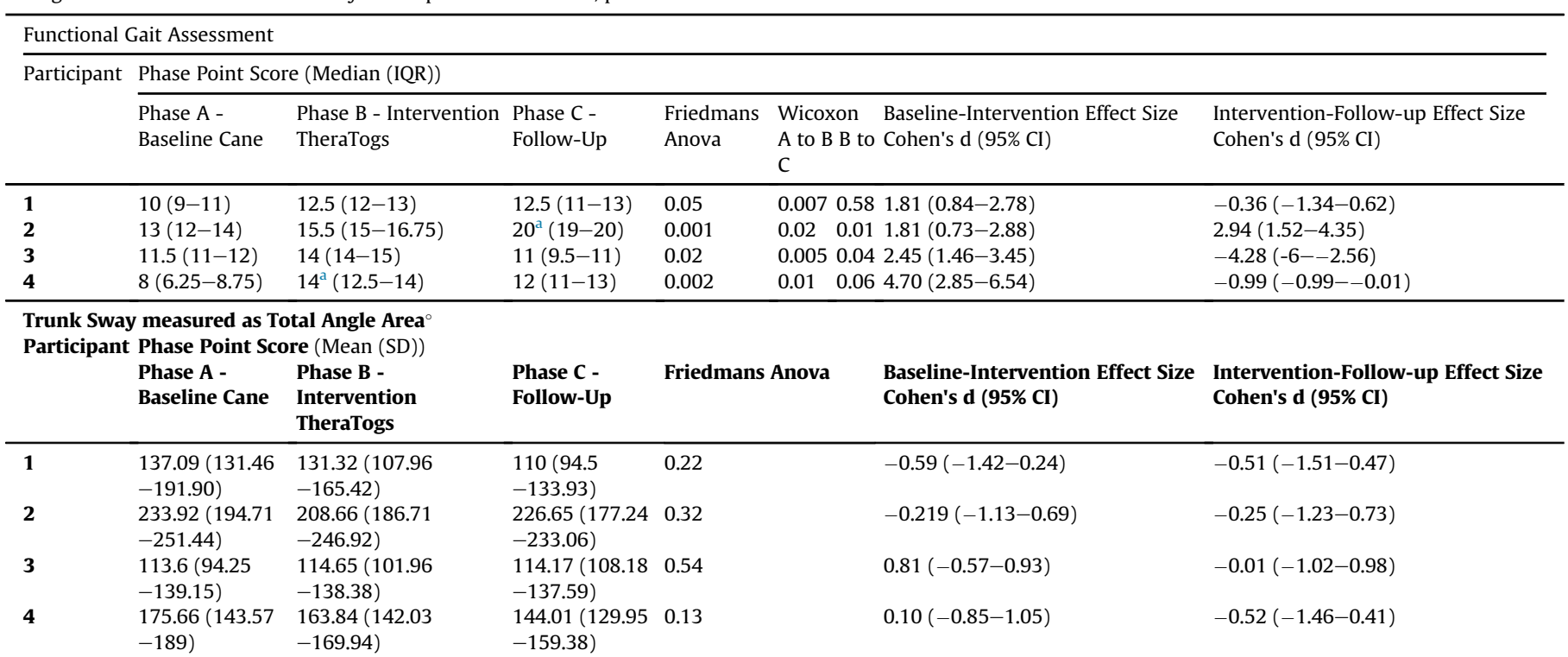

${ }^{a}$ FGA Estimated Minimally Clinically Important Difference in chronic stroke - 6 points.

2010; Neumann, 1999b) and changes to balance reactions (Beauchamp et al., 2009; Runge et al., 1999; Tung et al., 2015).

Although some change in scores may have been due to a learneffect due to frequent, repeated use of the same test, this is likely to have occurred during the first 9-12 repetitions of the test i.e. during phase $\mathrm{A}$, and is unlikely to account for the consistent jumps in performance between $\mathrm{A}$ and $\mathrm{B}$.

\subsection{Factors which may influence response}

Clinical presentation is likely to influence response. Participants $2 \& 4$ who showed the biggest improvements in FGA demonstrated the lowest sensory, proprioceptive and perceptual deficits. Further studies should attempt to identify relevant clinical parameters to predict response.

It remains unclear from these results how much improvement was due to TheraTogs and how much to reduced cane use. A combination of effects is likely. TheraTogs may increase muscle activity and provide stability, which in turn may enable a reduction of cane use. This would allow more normal afferent feedback and reduce the artificially increased base of support, thus forcing increased use of more healthy balance strategies.

There did not appear to be a correlation between either the number-of-hours TheraTogs was worn or the percentage of canereduction, and the degree of improvement. Several factors may have influenced this apparent lack of dose-response. It could be postulated that participants who walk more and spend less time being sedentary experience bigger effects from changing walkingaids. If this is the case, a dose-response relationship may be present but was not detected. Data was not collected regarding levels of activity during the different phases. Future studies should investigate whether activity levels influence effect-size and, whether change in assistive-device influences level of activity.

The response in the follow-up phase $\mathrm{C}$ was more varied ranging from improvement to stability to deterioration. These varied responses were likely due to the different assistive-devices chosen in phase $C$ as well as the individual clinical presentations and environmental factors such as caregiver support.

Changes in phase $C$ indicate that gains from phase $B$ were not stable and were influenced by ongoing use of walking-aids, suggesting that a longer intervention period may be necessary to create more established changes. This is supported by recent studies which indicate that motor-skill acquisition consists of two components which are time and dose-dependent. The first component of skill acquisition is "task-dependent adaptation" which represents brain plasticity and appears to occur after approximately 1000 repetitions. The second component is longterm change, which represents spinal-cord plasticity - the final common pathway of motor output. It appears that brain plasticity directs and maintains spinal plasticity and that approximately 2500 repetitions are required to produce permanent skill acquisition (Maguire, Sieben and de Bie, 2017; Norton and Wolpaw, 2018; Vahdat et al., 2015).

Reductions in trunk-sway during walking indicate increased stability and reflect improved balance. Therefore, gains in FGA scores would be expected to negatively correlate with trunk-sway values. This was the case in participants $1 \& 2$. However, in participants 3 \& 4, who showed most gains in FGA from A to B, mean values of trunk-sway in B increased slightly. This could be because increasing gait speed, which is a characteristic of improved gait function, increases trunk-sway (Goutier et al., 2010).

\subsection{Study design strengths and weaknesses}

As individual rather than group responses are investigated in $\mathrm{N}$ of- 1 series designs, broad inclusion and exclusion criteria could be defined allowing participants to represent a large section of the clinical population. However, the small number of participants included results in limited generalisability. The ability to closely follow and analyse individual rather than group effects of treatment, enabled the identification of possible factors which may influence response (sensory, proprioceptive and perceptual damage). These points need to be further investigated with larger participant numbers.

The implementation of this study, involving weekly measurements and fitting of the orthosis in clinic on measurement days, meant that blinding was not practically realisable. To minimise bias, measurements were carried out by two assessors at regular intervals to ensure standardised measurement procedures and to scrutinize performance interpretation. 

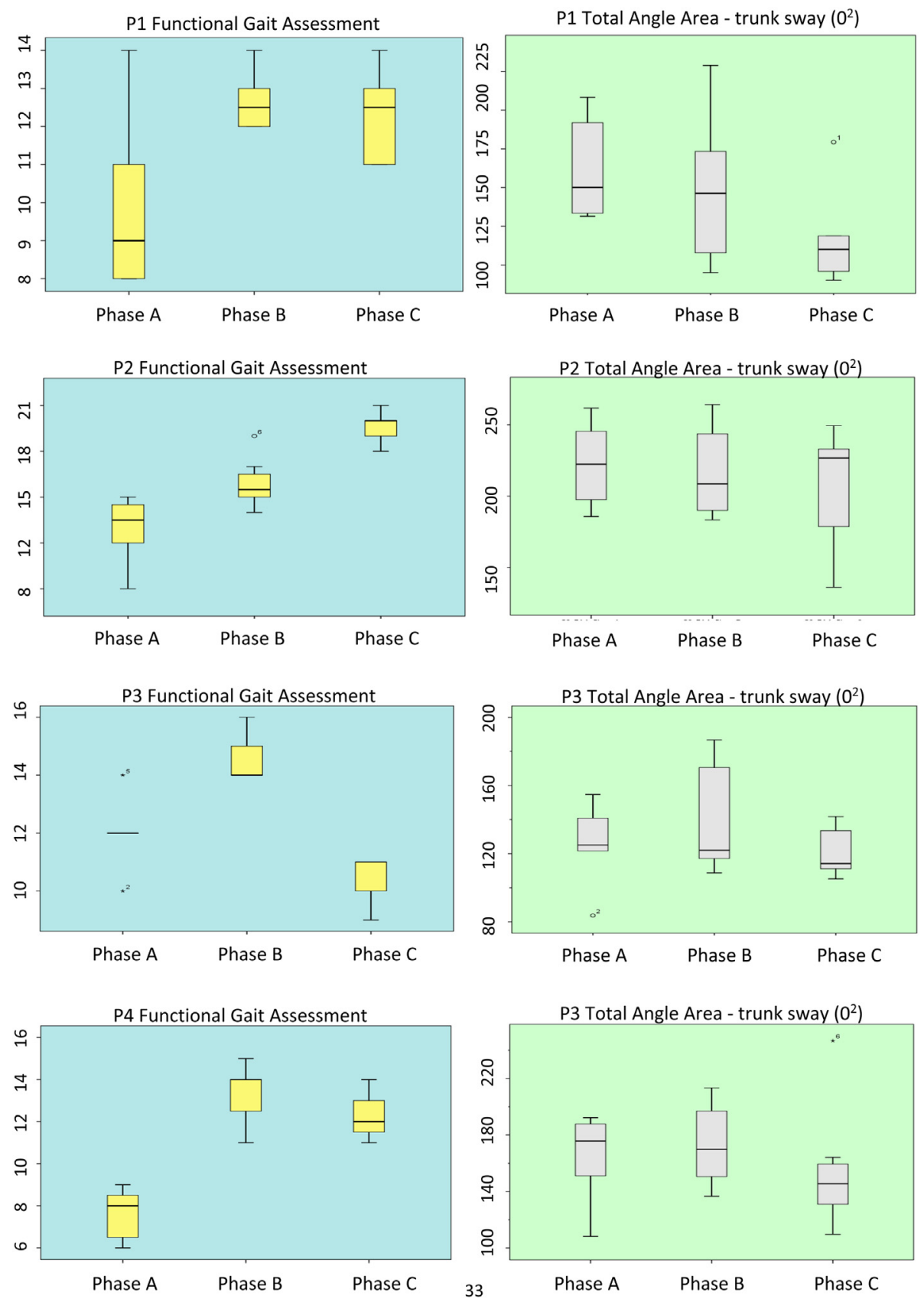

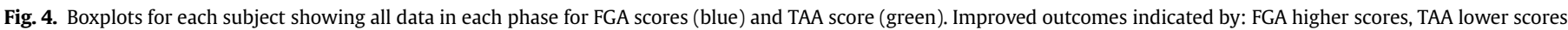
(For interpretation of the references to colour in this figure legend, the reader is referred to the Web version of this article.)

\subsection{Practicability and adherence}

Questionnaire results showed that participants found the individualised TheraTogs comfortable and felt it stabilized gait. Participant 3, whose orthotic garment was fitted by physiotherapists, reported particularly high levels of comfort. Adherence was good in phase B. Participants wore the orthosis on all days of phase B (100\% possible number of days) for between 8 and $11.3 \mathrm{~h}$. Caregivers reported that standardised application was quick and easy. The "invisibility" of the device may have been a factor which positively influenced adherence. However, despite positive feedback only one participant continued using the orthosis post intervention. Studies from other patient groups have indicated that even when orthoses are considered useful they can also be perceived as a "nuisance" and adherence drops off over time (Gruschke, ReindersMesselink, van der Vegt and van der Sluis, 2018). These issues have not been evaluated in stroke patients and future qualitative studies should investigate this phenomenon further.

Although no physical negative effects or harms were documented at any point during the study, P2 who walked independently in phase $\mathrm{C}$, did report feeling self-conscious about a more pronounced limp when walking without a cane.

\subsection{Clinical implications}

This N-of- 1 series indicates that walking-aids may have a specific influence on balance and walking ability in chronic stroke survivors, and that hand-free walking aid use (specifically in this 
study TheraTogs) combined with cane reduction may be more effective in promoting gait function than cane use alone. Alternative walking-aids which may have similar biomechanical effects and are designed to take higher loads, such as exoskeletons (Schiffman et al., 2008), could also be investigated in this patient population. Further studies, with larger participant numbers, are required to confirm these results, to identify whether these interventions are more effective with specific patient profiles and to further investigate dose-response relationships.

Motor control and functional recovery of both upper and lower limbs occurs for the most part within the first eight to twelve weeks post-stroke (Kwakkel et al., 2004; van Kordelaar et al., 2014). This period coincides with a time-dependent set of molecular and cellular changes which create a plasticity promoting environment within cortical, subcortical and spinal neural networks mediating functional improvement (Nudo, 2003, 2006; Sist et al., 2014). The effect of replacing canes with hands-free walking aids during the acute phase of rehabilitation, when gait recovery and neuroplasticity can be more directly affected, should also be evaluated.

\section{Clinical relevance}

- Although the recovery of gait and balance following stroke is multifactorial, walking aids appear to have a specific, clinically relevant and measurable effect.

- Walking-aids which do not use hands but which support hemiplegic muscle activity, thus providing stability, appear to increase recovery more than canes.

- This may be due to the physiological effects on joint loading, peripheral afferents, muscle action and balance reactions.

- Effects may be greatest in patients with minimal perceptual or sensory deficits.

\section{CRediT authorship contribution statement}

Clare C. Maguire: Conceptualization, Methodology, Writing original draft. Judith M. Sieben: Conceptualization, Methodology, Writing - original draft. Nathanael Lutz: Conceptualization, Methodology. Gisela van der Wijden: Conceptualization, Methodology. Heike Scheidhauer: Conceptualization, Methodology. RobertA. de Bie: Conceptualization, Methodology, Writing - original draft.

\section{Declaration of competing interest}

The authors declare there is no conflict of interest. No funding was provided for this project.

\section{Acknowledgements}

The authors would like to thank Florian Erzer PT MSc and Dr. M. Hund MD from the REHAB, Basel as well as Thomas Rosenheck, Hans-Peter Karrer and Bernadette Oberholzer from the Bildungszentrum Gesundheit Basel for their support during this research project.

\section{References}

Ajemian, S., Thon, D., Clare, P., Kaul, L., Zernicke, R.F., Loitz-Ramage, B., 2004. Caneassisted gait biomechanics and electromyography after total hip arthroplasty. Arch. Phys. Med. Rehabil. 85 (12), 1966-1971. S0003999304006434 [pii].

Alan, K., 2010. Single Case Research Designs: Methods for Clinical and Applied Settings. Oxford University Press.

Allet, L., Leemann, B., Guyen, E., Murphy, L., Monnin, D., Herrmann, F.R., Schnider, A., 2009. Effect of different walking aids on walking capacity of patients with poststroke hemiparesis. Arch. Phys. Med. Rehabil. 90 (8), 1408-1413. https:// doi.org/10.1016/j.apmr.2009.02.010.

Allum, J.H., Carpenter, M.G., 2005. A speedy solution for balance and gait analysis: angular velocity measured at the centre of body mass. Curr. Opin. Neurol. 18 (1), $15-21$.

Allum, J.H., Zamani, F., Adkin, A.L., Ernst, A., 2002. Differences between trunk sway characteristics on a foam support surface and on the Equitest ankle-swayreferenced support surface. Gait Posture 16 (3), 264-270. S0966636202000115 [pii].

Andrenelli, E., Ippoliti, E., Coccia, M., Millevolte, M., Cicconi, B., Latini, L., et al., 2015 Features and predictors of activity limitations and participation restriction 2 years after intensive rehabilitation following first-ever stroke. Eur. J. Phys. Rehabil. Med. 51 (5), 575-585.

Backman, C.L., Harris, S.R., 1999. Case studies, single-subject research, and N of 1 randomized trials: comparisons and contrasts. Am. J. Phys. Med. Rehabil. 78 (2), $170-176$.

Bateni, H., Maki, B.E., 2005. Assistive devices for balance and mobility: benefits, demands, and adverse consequences. Arch. Phys. Med. Rehabil. 86 (1), 134-145.

Beauchamp, M.K., Skrela, M., Southmayd, D., Trick, J., Kessel, M.V., Brunton, K., et al., 2009. Immediate effects of cane use on gait symmetry in individuals with subacute stroke. Physiother. Can. 61 (3), 154-160. https://doi.org/10.3138/ physio.61.3.154.

Brown, M., Levack, W., McPherson, K.M., Dean, S.G., Reed, K., Weatherall, M., Taylor, W.J., 2014. Survival, momentum, and things that make me "me": patients' perceptions of goal setting after stroke. Disabil. Rehabil. 36 (12), 1020-1026. https://doi.org/10.3109/09638288.2013.825653.

Buurke, J.H., Hermens, H.J., Erren-Wolters, C.V., Nene, A.V., 2005. The effect of walking aids on muscle activation patterns during walking in stroke patients. Gait Posture 22 (2), 164-170. https://doi.org/10.1016/j.gaitpost.2004.09.003. S0966-6362(04)00165-1 [pii].

Byiers, B.J., Reichle, J., Symons, F.J., 2012. Single-subject experimental design for evidence-based practice. Am. J. Speech Lang. Pathol 21 (4), 397-414. https:// doi.org/10.1044/1058-0360(2012/11-0036.

Cha, Y.J., 2015. Do traditionally recommended cane lengths equally influence walking in patients after stroke? Disabil Health J 8 (1), 136-139. https://doi.org/ 10.1016/j.dhjo.2014.07.001.

Deng, H., Kimberley, T.J., Durfee, W.K., Dressler, B.L., Steil, C., Carey, J.R., 2013. Combined statistical analysis method assessing fast versus slow movement training in a patient with cerebellar stroke: a single-case study. Phys. Ther. 93 (5), 649-660. https://doi.org/10.2522/ptj.20120121.

Dietz, V., 2003. Spinal cord pattern generators for locomotion. Clin. Neurophysiol. 114 (8), 1379-1389.

Dietz, V., 2012. Neuronal plasticity after a human spinal cord injury: positive and negative effects. Exp. Neurol. 235 (1), 110-115. https://doi.org/10.1016/ j.expneurol.2011.04.007.

Dietz, V., Müller, R., Colombo, G., 2002. Locomotor activity in spinal man: significance of afferent input from joint and load receptors. Brain 125 (Pt 12), 2626-2634.

Fini, N.A., Holland, A.E., Keating, J., Simek, J., Bernhardt, J., 2017. How physically active are people following stroke? Systematic review and quantitative synthesis. Phys. Ther. 97 (7), 707-717. https://doi.org/10.1093/ptj/pzx038.

Folstein, M.F., Folstein, S.E., McHugh, P.R., 1975. Mini-mental state". A practical method for grading the cognitive state of patients for the clinician. J. Psychiatr. Res. 12 (3), 189-198, 0022-3956(75)90026-6 [pii].

Goutier, K.M., Jansen, S.L., Horlings, C.G., Küng, U.M., Allum, J.H., 2010. The influence of walking speed and gender on trunk sway for the healthy young and older adults. Age Ageing 39 (5), 647-650. https://doi.org/10.1093/ageing/afq066.

Gruschke, J.S., Reinders-Messelink, H.A., van der Vegt, A.E., van der Sluis, C.K., 2018. User perspectives on orthoses for thumb carpometacarpal osteoarthritis. J. Hand Ther. https://doi.org/10.1016/j.jht.2018.04.006.

Hamzat, T.K., Kobiri, A., 2008. Effects of walking with a cane on balance and social participation among community-dwelling post-stroke individuals. Eur. J. Phys. Rehabil. Med. 44 (2), 121-126.

Hart, T., Bagiella, E., 2012. Design and implementation of clinical trials in rehabilitation research. Arch. Phys. Med. Rehabil. 93 (8 Suppl. 1), S117-S126. https:// doi.org/10.1016/j.apmr.2011.11.039.

Kim, O., Kim, J.H., 2015. Falls and use of assistive devices in stroke patients with hemiparesis: association with balance ability and fall efficacy. Rehabil. Nurs. 40 (4), 267-274. https://doi.org/10.1002/rnj.173.

Kwakkel, G., Kollen, B., Lindeman, E., 2004. Understanding the pattern of functional recovery after stroke: facts and theories. Restor. Neurol. Neurosci. 22 (3-5), 281-299.

Leddy, A.L., Crowner, B.E., Earhart, G.M., 2011. Functional gait assessment and balance evaluation system test: reliability, validity, sensitivity, and specificity for identifying individuals with Parkinson disease who fall. Phys. Ther. 91 (1), 102-113. https://doi.org/10.2522/ptj.20100113.

Lin, J.H., Hsu, M.J., Hsu, H.W., Wu, H.C., Hsieh, C.L., 2010. Psychometric comparisons of 3 functional ambulation measures for patients with stroke. Stroke 41 (9), 2021-2025. https://doi.org/10.1161/STROKEAHA.110.589739.

Maeda, N., Urabe, Y., Murakami, M., Itotani, K., Kato, J., 2015. Discriminant analysis for predictor of falls in stroke patients by using the Berg Balance Scale. Singap. Med. J. 56 (5), 280-283. https://doi.org/10.11622/smedj.2015033.

Maguire, C., Sieben, J.M., Frank, M., Romkes, J., 2010. Hip abductor control in walking following stroke - the immediate effect of canes, taping and TheraTogs on gait Clin. Rehabil. 24 (1), 37-45. https://doi.org/10.1177/0269215509342335, 0269215509342335 [pii]. 
Maguire, C., Sieben, J.M., Scheidhauer, H., Romkes, J., Suica, Z., de Bie, R.A., 2016. The effect of crutches, an orthosis TheraTogs, and no walking aids on the recovery of gait in a patient with delayed healing post hip fracture: a case report. Physiother. Theory Pract. 32 (1), 69-81. https://doi.org/10.3109/ 09593985.2015.1075640.

Maguire, C.C., Sieben, J.M., de Bie, R.A., 2017. The influence of walking-aids on the plasticity of spinal interneuronal networks, central-pattern-generators and the recovery of gait post-stroke. A literature review and scholarly discussion. J. Bodyw. Mov. Ther. 21 (2), 422-434. https://doi.org/10.1016/ j.jbmt.2016.09.012.

Maki, B.E., Mcllroy, W.E., 1997. The role of limb movements in maintaining upright stance: the "change-in-support" strategy. Phys. Ther. 77 (5), 488-507.

Marklund, I., Klässbo, M., 2006. Effects of lower limb intensive mass practice in poststroke patients: single-subject experimental design with long-term followup. Clin. Rehabil. 20 (7), 568-576.

Michael, K.M., Allen, J.K., Macko, R.F., 2005. Reduced ambulatory activity after stroke: the role of balance, gait, and cardiovascular fitness. Arch. Phys. Med. Rehabil. 86 (8), 1552-1556. https://doi.org/10.1016/j.apmr.2004.12.026.

Neumann, D.A., 1999a. An electromyographic study of the hip abductor muscles as subjects with a hip prosthesis walked with different methods of using a cane and carrying a load. Phys. Ther. 79 (12), 1163-1173 discussion 1174-1166.

Neumann, D.A., 1999b. An electromyographic study of the hip abductor muscles as subjects with a hip prosthesis walked with different methods of using a cane and carrying a load. Phys. Ther. 79 (12), 1163-1173 discussion 1174-1166.

Norlander, A., Carlstedt, E., Jonsson, A.C., Lexell, E.M., Stahl, A., Lindgren, A., Iwarsson, S., 2016. Long-term predictors of social and leisure activity 10 Years after stroke. PloS One 11 (2), e0149395. https://doi.org/10.1371/ journal.pone.0149395.

Norton, J.J.S., Wolpaw, J.R., 2018. Acquisition, maintenance, and therapeutic use of a simple motor skill. Curr Opin Behav Sci 20, 138-144. https://doi.org/10.1016/ j.cobeha.2017.12.021.

Nourbakhsh, M.R., Ottenbacher, K.J., 1994. The statistical analysis of single-subject data: a comparative examination. Phys. Ther. 74 (8), 768-776.

Nudo, R.J., 2003. Adaptive plasticity in motor cortex: implications for rehabilitation after brain injury. J. Rehabil. Med. 41 (Suppl. 1), 7-10.

Nudo, R.J., 2006. Mechanisms for recovery of motor function following cortical damage. Curr. Opin. Neurobiol. 16 (6), 638-644. https://doi.org/10.1016/ j.conb.2006.10.004. S0959-4388(06)00144-9 [pii].

Ocebm, L.o.E.W. G., 2011. Levels of evidence oxford centre for evidence-based medicine. http://www.cebm.net/index.aspx? $0=5653$.

Paquet, N., Desrosiers, J., Demers, L., Robichaud, L., 2009. Predictors of daily mobility skills 6 months post-discharge from acute care or rehabilitation in older adults with stroke living at home. Disabil. Rehabil. 31 (15), 1267-1274. https://doi.org/ 10.1080/09638280802621374.

Patterson, S.L., Forrester, L.W., Rodgers, M.M., Ryan, A.S., Ivey, F.M., Sorkin, J.D., Macko, R.F., 2007. Determinants of walking function after stroke: differences by deficit severity. Arch. Phys. Med. Rehabil. 88 (1), 115-119. https://doi.org/ 10.1016/j.apmr.2006.10.025.

Paul, L., Brewster, S., Wyke, S., Gill, J.M., Alexander, G., Dybus, A., Rafferty, D., 2016. Physical activity profiles and sedentary behaviour in people following stroke: a cross-sectional study. Disabil. Rehabil. 38 (4), 362-367. https://doi.org/10.3109/ 09638288.2015 .1041615$.

Price, R., Choy, N.L., 2018. Investigating the relationship of the functional gait assessment to spatiotemporal parameters of gait and quality of life of individuals with stroke. J. Geriatr. Phys. Ther. https://doi.org/10.1519/ jpt.0000000000000173.

Runge, C.F., Shupert, C.L., Horak, F.B., Zajac, F.E., 1999. Ankle and hip postural strategies defined by joint torques. Gait Posture 10 (2), 161-170.

Schiffman, J.M., Gregorczyk, K.N., Bensel, C.K., Hasselquist, L., Obusek, J.P., 2008. The effects of a lower body exoskeleton load carriage assistive device on limits of stability and postural sway. Ergonomics 51 (10), 1515-1529. https://doi.org/
$10.1080 / 00140130802248084$

Sist, B., Fouad, K., Winship, I.R., 2014. Plasticity beyond peri-infarct cortex: spinal up regulation of structural plasticity, neurotrophins, and inflammatory cytokines during recovery from cortical stroke. Exp. Neurol. 252, 47-56. https://doi.org 10.1016/j.expneurol.2013.11.019.

Son, S.M., Kwon, J.W., Nam, S.H., Lee, N.K., Kim, K., Kim, C.S., 2012. Adverse effects of motor-related symptoms on the ipsilateral upper limb according to long-term cane usage. NeuroRehabilitation 31 (2), 137-141. https://doi.org/10.3233/nre2012-0782.

Thieme, H., Ritschel, C., Zange, C., 2009. Reliability and validity of the functional gait assessment (German version) in subacute stroke patients. In: Arch Phys Med Rehabil, vol. 90, pp. 1565-1570. United States.

Tilson, J.K. Wu, S.S, Cen, S.Y, Feng, O, Rose, D.R, Behrman, A.L, et al, 2012 Characterizing and identifying risk for falls in the LEAPS study: a randomized clinical trial of interventions to improve walking poststroke. In: Stroke, vol. 43 pp. 446-452. United States.

Tung, J.Y., Chee, J.N., Zabjek, K.F., McIlroy, W.E., 2015. Combining ambulatory and laboratory assessment of rollator use for balance and mobility in neurologic rehabilitation in-patients. Disabil. Rehabil. Assist. Technol. 10 (5), 407-414. https://doi.org/10.3109/17483107.2014.908243.

Tyson, S.F., 1999. Trunk kinematics in hemiplegic gait and the effect of walking aids Clin. Rehabil. 13 (4), 295-300.

Ustun, T.B., Chatterji, S., Bickenbach, J., Kostanjsek, N., Schneider, M., 2003. The International Classification of Functioning, Disability and Health: a new tool for understanding disability and health. Disabil. Rehabil. 25 (11-12), 565-571. https://doi.org/10.1080/0963828031000137063.

Vahdat, S., Lungu, O., Cohen-Adad, J., Marchand-Pauvert, V., Benali, H., Doyon, J. 2015. Simultaneous brain-cervical cord fMRI reveals intrinsic spinal cord plasticity during motor sequence learning. PLoS Biol 13 (6), e1002186. https:// doi.org/10.1371/journal.pbio.1002186.

van Kordelaar, J., van Wegen, E., Kwakkel, G., 2014. Impact of time on quality of motor control of the paretic upper limb after stroke. Arch. Phys. Med. Rehabil. 95 (2), 338-344. https://doi.org/10.1016/j.apmr.2013.10.006.

van Mierlo, M.L., van Heugten, C.M., Post, M.W., Hajos, T.R., Kappelle, L.J., VisserMeily, J.M., 2016. Quality of life during the first two years post stroke: the Restore4Stroke cohort study. Cerebrovasc. Dis. 41 (1-2), 19-26. https://doi.org $10.1159 / 000441197$.

Veerbeek, Wegen, v., Peppen, v., Hendriks, Rietberg, Wees, v. d., Kwakkel, ., 2014. Royal Dutch Society for Physical Therapy - Clinical Practice Guideline for Physical Therapy in Patients with Stroke.

Verma, R., Arya, K.N., Sharma, P., Garg, R.K., 2012. Understanding gait control in post-stroke: implications for management. J. Bodyw. Mov. Ther. 16 (1), 14-21. https://doi.org/10.1016/j.jbmt.2010.12.005.

Vohra, S., Shamseer, L., Sampson, M., Bukutu, C., Schmid, C.H., Tate, R., et al., 2016. CONSORT extension for reporting N-of-1 trials (CENT) 2015 Statement. J. Clin. Epidemiol. 76, 9-17. https://doi.org/10.1016/j.jclinepi.2015.05.004.

Walker, M.L., Austin, A.G., Banke, G.M., Foxx, S.R., Gaetano, L., Gardner, L.A., et al. 2007. Reference group data for the functional gait assessment. Phys. Ther. 87 (11), 1468-1477. https://doi.org/10.2522/ptj.20060344.

Wang, R., Langhammer, B., 2017. Predictors of quality of life for chronic stroke survivors in relation to cultural differences: a literature review. Scand. J. Caring Sci. https://doi.org/10.1111/scs.12533.

West, B.A., Bhat, G., Stevens, J., Bergen, G., 2015. Assistive device use and mobility-

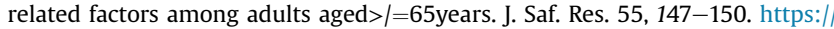
doi.org/10.1016/j.jsr.2015.08.010.

Wrisley, D.M., Kumar, N.A., 2010. Functional gait assessment: concurrent, discriminative, and predictive validity in community-dwelling older adults. Phys. Ther 90 (5), 761-773. https://doi.org/10.2522/ptj.20090069.

Wrisley, D.M., Marchetti, G.F., Kuharsky, D.K., Whitney, S.L., 2004. Reliability, internal consistency, and validity of data obtained with the functional gait assessment. Phys. Ther. 84 (10), 906-918. 